\title{
Incisional hernia after minimally invasive gastrectomy in gastric cancer patients
}

\author{
Sung Chun Cho ${ }^{1}$, Bang Wool Eom, ${ }^{1,2}$, Hong Man Yoon ${ }^{1,2}$, Young-Woo Kim ${ }^{1,2,3}$, Keun Won Ryư ${ }^{1,2}$ \\ ${ }^{1}$ Department of Surgery, National Cancer Center, Goyang, Korea \\ ${ }^{2}$ Center for Gastric Cancer, National Cancer Center, Goyang, Korea \\ ${ }^{3}$ Department of Cancer Control and Population Health, National Cancer Center Graduate School of Cancer Science and Policy, Goyang, Korea
}

Purpose: Although there are several studies on the incidence and risk factors for incisional hernia (IH) after open surgery, data about IH after minimally invasive surgery (MIS) for gastric cancer is rare. This study aimed to identify the incidence and risk factors for IH after MIS in gastric cancer patients.

Methods: We analyzed the clinicopathologic data of patients who had laparoscopic or robotic gastric cancer surgeries between January 2006 and July 2019 at National Cancer Center, South Korea. Risk factors for development of $\mathrm{IH}$ were investigated with univariate and multivariate analyses.

Results: A total of 2,769 patients underwent laparoscopic-assisted or robot-assisted gastrectomy with extracorporeal gastric resection and reconstruction, while 1,469 underwent totally laparoscopic or totally robotic gastrectomy (TLRG) with intracorporeal gastric resection and reconstruction. IH repair was performed in 23 patients ( $0.5 \%)$ after gastric cancer surgery. In the multivariate analysis, female sex (odds ratio [OR], 5.23 ; 95\% confidence interval [CI], 2.03-13.43; $p=0.001$ ), high body mass index (BMI) of $\geq 25 \mathrm{~kg} / \mathrm{m}^{2}$ (OR, 4.23; 95\% CI, 1.73-10.35; $p=0.002$ ), larger tumor size (OR, 21.67; 95\% CI, 5.37-87.34; $p<0.001$ ), and intracorporeal procedure (OR, 5.63; 95\% CI, 2.15-14.61; $p<0.001)$ were independent significant risk factors for $\mathrm{IH}$.

Conclusion: IH after MIS for gastric cancer is not common. Female sex, high BMI, large tumor size, and intracorporeal procedure were significant risk factors for it in this study. Therefore, in patients with risk factors, surgeons should cautiously close the abdominal wall access wound after MIS for gastric cancer, to prevent $\mathrm{IH}$.

Keywords: Stomach neoplasms, Minimally invasive surgical procedures, Incisional hernia

This is an Open Access article distributed under the terms of the Creative Commons Attribution Non-Commercial License (http:// creativecommons.org/licenses/by-nc/4.0/) which permits unrestricted non-commercial use, distribution, and reproduction in any medium, provided the original work is properly cited.
Received September 10, 2020

Revised 1st October 28, 2020

2nd November 12, 2020

3rd November 13, 2020

Accepted November 13, 2020

Corresponding author

Keun Won Ryu

Center for Gastric Cancer, National

Cancer Center, 323 Ilsan-ro,

Ilsandong-gu, Goyang 10408, Korea

Tel: +82-31-920-1628

Fax: +82-31-920-0069

E-mail: docryu@ncc.re.kr

ORCID:

https://orcid.org/0000-0002-5935-9777

\section{INTRODUCTION}

Incisional hernia $(\mathrm{IH})$ is a common long-term complication after abdominal surgery. Its incidence rate after midline laparotomy ranges widely from $9 \%$ to $20 \%$ [1-3]. Since it uses smaller incisions than open surgery, laparoscopic surgery has many advantages such as reduced blood loss, less pain, and faster recovery, and it is being gradually used in a wide range of applications [4-6]. Fur- thermore, a systematic review and meta-analysis showed that the rate of IH after laparoscopic surgery is significantly lower than after open surgery [7].

Recently, laparoscopic gastrectomy has become more widely used for gastric cancer surgery. Several large-scale randomized clinical trials that compared laparoscopic gastrectomy and open gastrectomy in gastric cancer patients showed the non-inferiority of laparoscopic surgery with regard to short-term and long-term 
surgical outcomes [8-10]. Initially, laparoscopic-assisted gastrectomy (LAG), with extracorporeal gastric resection and reconstruction through additional minilaparotomy incision, was mainly performed. However, nowadays, advancement in laparoscopic surgical equipment and surgical technique has led to increased use of totally laparoscopic gastrectomy (TLG), with intracorporeal gastric resection and reconstruction, and specimen removal through extension of umbilical port. TLG has several advantages over LAG, including smaller wounds and less invasiveness [11,12]. Furthermore, robotic surgery is also performed as a modality of minimally invasive surgery (MIS), and the number of cases managed this way has recently increased $[13,14]$.

Several variables, such as specimen extraction site, high body mass index (BMI), and comorbidity, have been identified as independent risk factors associated with $\mathrm{IH}$ after laparoscopic colorectal surgery [15-17]. However, studies about the incidence and risk factors for $\mathrm{IH}$ after MIS for gastric cancer are few.

The purpose of this study was to identify the incidence rate and risk factors for IH after MIS in gastric cancer patients.

\section{MATERIALS AND METHODS}

\section{Study design}

This study was a retrospective case-control study. We analyzed the clinicopathologic data of gastric cancer patients who had laparoscopic or robotic gastric cancer surgeries between January 2006 and July 2019 in National Cancer Center, South Korea. Patients were divided into two groups depending on occurrence of $\mathrm{IH}$ after the gastric cancer surgery. Risk factors for development of IH in these patients were investigated by univariate and multivariate analyses.

\section{Surgical procedures}

In this study, two types of surgery were defined as extracorporeal or intracorporeal procedure, depending on gastric resection and reconstruction method. Laparoscopic or robot-assisted gastrectomy (LRAG) consisted of gastric resection and specimen removal and reconstruction through additional minilaparotomy, and it included distal gastrectomy, total gastrectomy, proximal gastrectomy, and pylorus-preserving gastrectomy [18]. Totally laparoscopic or robotic gastrectomy (TLRG) consisted of intracorporeal gastric resection and reconstruction, and the specimen was removed by extension of the umbilical port; it included the same types of gastrectomy as are done in extracorporeal anastomosis. In extracorporeal procedure, we made one camera port at the umbilicus and four trocar ports at the left upper quadrant, left lower quadrant, right upper quadrant, and right lower quadrant. All surgical procedures for dissection, except gastric resection and reconstruction and specimen extraction, were performed using laparoscopy or robotics. Surgeons performed additional vertical or transverse minilaparotomy in the epigastric area for gastric resection, specimen extraction, and extracorporeal anastomosis. In intracorporeal procedure, port sites were the same as for extracorporeal anastomosis, but surgeons performed a minilaparotomy by extending the umbilical port site instead of making another epigastric incision. All surgical procedures, including gastric resection and reconstruction, were performed intracorporeally, and the specimen was extracted through the minilaparotomy.

The minilaparotomy incisions of LRAG and umbilical extension wounds of TLRG were closed either layer by layer or as one layer, using absorbable suture materials such as Vicryl (Ethicon, Somerville, NJ, USA) or Maxon (Medtronic, Minneapolis, MN, USA), and with continuous or simple interrupted suture technique according to each surgeon's preference.

\section{Statistical analysis}

For the BMI, we divided the group by $<25 \mathrm{~kg} / \mathrm{m}^{2}$ and $\geq 25 \mathrm{~kg} / \mathrm{m}^{2}$. And for the tumor size, we divided the group by $<10 \mathrm{~cm}$ and $\geq 10 \mathrm{~cm}$. In general, statistical analysis was performed based on the median or mean tumor size, but we considered the clinically meaningful size as $10 \mathrm{~cm}$ and analyzed it based on this.

Continuous variables were evaluated with Student $t$ test. Categorical data were compared with chi-square test or Fisher exact test. Multivariate analysis of risk factors for $\mathrm{IH}$ was performed with logistic regression.

All analyses were performed with SAS version 9.1.3 for Windows (SAS Institute, Cary, NC, USA). The $p$ values of $<0.05$ were considered statistically significant.

\section{RESULTS}

Between January 1, 2006 and July 31, 2020, 4,238 patients underwent laparoscopic or robotic gastric cancer surgery in the study center. Among them, 2,769 underwent LRAG, while 1,469 underwent TLRG. IH repair was performed in 23 patients $(0.5 \%)$ after gastric cancer surgery, with median follow-up period of 43 months.

The baseline clinicopathologic characteristics of enrolled patients are shown in Table 1 . Male patients were dominant in the non-IH group ( $\mathrm{n}=2,608,61.9 \%$ ), while female patients were dominant in the $\mathrm{IH}$ group $(\mathrm{n}=17,73.9 \%)$. Median BMI was 23.9 $\mathrm{kg} / \mathrm{m}^{2}$ in non-IH group and $26.6 \mathrm{~kg} / \mathrm{m}^{2}$ in $\mathrm{IH}$ group. Median age was 59.1 years in non-IH group and 61.3 years in $\mathrm{IH}$ group. The incidence rates of $\mathrm{IH}$ in extracorporeal and intracorporeal procedures were $0.2 \%$ and $1 \%$, respectively $(n=8$ and $n=15$, respectively; $p=0.002$ ). The median interval from gastric cancer 
Table 1. Demographics of enrolled patients

\begin{tabular}{|c|c|c|c|}
\hline Variable & Non-IH group & IH group & $p$ value \\
\hline No. of patients & 4,215 & 23 & \\
\hline Age (yr) & $59.1 \pm 12.0$ & $61.3 \pm 13.4$ & 0.367 \\
\hline Sex & & & $<0.001$ \\
\hline Male & 2,608 (61.9) & $6(26.1)$ & \\
\hline Female & $1,607(38.1)$ & $17(73.9)$ & \\
\hline Body mass index $\left(\mathrm{kg} / \mathrm{m}^{2}\right)$ & $23.9 \pm 3.3$ & $26.6 \pm 4.4$ & $<0.001$ \\
\hline ASA PS classification & & & 0.849 \\
\hline 1 & $1,433(34.0)$ & $7(30.4)$ & \\
\hline$\|$ & $2,543(60.3)$ & $15(65.2)$ & \\
\hline$\geq \| I$ & $239(5.7)$ & $1(4.3)$ & \\
\hline Tumor size (cm) & $3.29 \pm 2.0$ & $4.5 \pm 3.4$ & $<0.001$ \\
\hline Histology & & & 0.222 \\
\hline WD & $774(18.4)$ & $2(8.7)$ & \\
\hline MD & $751(17.8)$ & $5(21.7)$ & \\
\hline PD & $1,126(26.7)$ & $4(17.4)$ & \\
\hline SRC & $1,506(35.7)$ & $12(52.2)$ & \\
\hline Other & $58(1.4)$ & $0(0)$ & \\
\hline Pathologic stage & & & 0.914 \\
\hline 1 & $3,680(87.3)$ & $20(87.0)$ & \\
\hline$\|$ & 391 (9.3) & $2(8.7)$ & \\
\hline || & $134(3.2)$ & $1(4.3)$ & \\
\hline IV & $10(0.2)$ & $0(0)$ & \\
\hline Surgical approach & & & 0.511 \\
\hline Laparoscopic & $3,874(91.9)$ & $22(95.7)$ & \\
\hline Robotic & $341(8.1)$ & $1(4.3)$ & \\
\hline Gastric resection & & & 0.178 \\
\hline PPG & $272(6.5)$ & $0(0)$ & \\
\hline $\mathrm{DG}$ & $3,416(81.0)$ & $19(82.6)$ & \\
\hline$P G$ & $118(2.8)$ & $0(0)$ & \\
\hline $\mathrm{TG}$ & $409(9.7)$ & $4(17.4)$ & \\
\hline Anastomosis method & & & 0.002 \\
\hline Extracorporeal & $2,761(65.5)$ & $8(34.8)$ & \\
\hline Intracorporeal & $1,454(34.5)$ & $15(65.2)$ & \\
\hline LN dissection & & & 0.016 \\
\hline$<\mathrm{D} 2$ & $1,803(42.8)$ & $9(39.1)$ & \\
\hline$\geq \mathrm{D} 2$ & 2,412 (57.2) & $14(60.9)$ & \\
\hline LN harvest & $36.0 \pm 13.5$ & $39.3 \pm 13.1$ & 0.717 \\
\hline Adjuvant chemotherapy & 445 (10.6) & $3(13.0)$ & 0.149 \\
\hline Days on admission & $8.3 \pm 5.9$ & $8.4 \pm 3.9$ & 0.934 \\
\hline Postoperative complication) & $159(3.8)$ & $2(8.7)$ & 0.217 \\
\hline
\end{tabular}

Values are presented as number only, mean \pm standard deviation, or number $(\%)$.

IH, incisional hernia; ASA PS, American Society of Anesthesiologists physical status; WD, well-differentiated; MD, moderately-differentiated; PD, poorlydifferentiated; SRC, signet ring cell; PPG, pylorus preserving gastrectomy; DG, distal gastrectomy; PG, proximal gastrectomy; TG, total gastrectomy; LN, lymph node.

${ }^{\text {a) }}$ Clavien-Dindo classification $\geq 3$. 
Table 2. Risk factors for incisional hernia after laparoscopic gastric cancer surgery

\begin{tabular}{|c|c|c|c|c|}
\hline \multirow{2}{*}{ Variable } & \multicolumn{2}{|c|}{ Univariate analysis } & \multicolumn{2}{|c|}{ Multivariate analysis } \\
\hline & OR (95\% Cl) & $p$ value & OR (95\% Cl) & $p$ value \\
\hline \multicolumn{5}{|l|}{ Sex } \\
\hline Male & 1 & & 1 & \\
\hline Female & $4.11(1.55-10.95)$ & $<0.001$ & $5.23(2.03-13.43)$ & 0.001 \\
\hline \multicolumn{5}{|c|}{ Body mass index $\left(\mathrm{kg} / \mathrm{m}^{2}\right)$} \\
\hline$<25$ & 1 & & 1 & \\
\hline$\geq 25$ & 3.01 (1.30-6.97) & 0.007 & $4.23(1.73-10.35)$ & 0.002 \\
\hline \multicolumn{5}{|l|}{ Tumor size (cm) } \\
\hline$<10$ & 1 & & 1 & \\
\hline$\geq 10$ & 16.45 (4.69-57.68) & $<0.001$ & 21.67 (5.37-87.34) & $<0.001$ \\
\hline \multicolumn{5}{|c|}{ Anastomosis method } \\
\hline Extracorporeal & 1 & & 1 & \\
\hline Intracorporeal & 6.74 (2.389-19.02) & 0.002 & $5.63(2.15-14.61)$ & $<0.001$ \\
\hline \multicolumn{5}{|l|}{ LN dissection } \\
\hline$<\mathrm{D} 2$ & 1 & & 1 & \\
\hline$\geq \mathrm{D} 2$ & $3.34(1.11-10.04)$ & 0.016 & 2.58 (1.05-6.64) & 0.050 \\
\hline
\end{tabular}

$\mathrm{OR}$, odds ratio; $\mathrm{Cl}$, confidence interval; LN, lymph node.

surgery to IH repair surgery was 14 months (14 \pm 12 months).

Table 2 shows univariate and multivariate analyses of risk factors for IH after gastric cancer surgery. Incidence rate of $\mathrm{IH}$ was significantly higher among female patients and those who had intracorporeal procedure ( $p=0.001$ and $p<0.001$, respectively). BMI was significantly higher and tumor size was significantly larger in the IH group ( $p=0.002$ and $p<0.001$, respectively). In the multivariate analysis, female sex, higher BMI $\left(\geq 25 \mathrm{~kg} / \mathrm{m}^{2}\right)$, larger tumor size $(\geq 10 \mathrm{~cm})$, and intracorporeal procedure were independent significant risk factors for IH. D2 lymph node dissection was a significant risk factor for $\mathrm{IH}$ in univariate analysis, but it was not significantly different between the IH and non-IH groups in multivariate analysis.

Of the patients who had extracorporeal procedure, two had IH in the umbilical area, two in the epigastric area, and five at other port sites. All of the patients who had intracorporeal procedure had IH in the umbilical area (Table 3). Application of mesh during $\mathrm{IH}$ repair was based on the surgeon's preference; thus, $14 \mathrm{pa}$ tients received mesh reinforcement, while nine patients did not. There were two cases of reoperation for IH repair and both occurred in patients who did not have mesh reinforcement during the first hernia repair.
Table 3. Characteristics of incisional hernia in the present study

\begin{tabular}{lc}
\hline \multicolumn{1}{c}{ Variable } & $\begin{array}{c}\text { Patient } \\
(\mathrm{n}=23)\end{array}$ \\
\hline Hernia site & 9 \\
Laparoscopic or robot-assisted gastrectomy & $5(55.6)$ \\
Umbilical area & $2(22.2)$ \\
Epigastric area & $2(22.2)$ \\
Other port sites & 14 \\
Totally laparoscopic or robotic gastrectomy & $14(100)$ \\
Umbilical area & $0(0)$ \\
Other port sites & 23 \\
Mesh application during incisional hernia repair & $14(60.9)$ \\
Mesh reinforcement & $9(39.1)$ \\
No mesh reinforcement & 2 \\
Reoperation of recurrent incisional hernia & $0(0)$ \\
Mesh reinforcement during the first hernia repair & $2(100)$ \\
\hline
\end{tabular}

Values are presented as number (\%). 


\section{DISCUSSION}

MIS is becoming popular for stomach surgeries. Incidence and risk factors for IH after open surgery are well known, but study of IH after MIS for gastric cancer is limited [19-21]. Recently, although not with respect to gastric cancer surgery, there have been reports that IH occurs more frequently in single-incision laparoscopic surgery (SILS) than in laparoscopic surgery using multiple ports [22-26]. This is presumed to be due to the large umbilical port made in SILS. In recent years, TLRG, with intracorporeal gastric resection and reconstruction and specimen removal through extension of the umbilical port, tends to be preferred because it eliminates the need for additional minilaparotomy. Moreover, SILS is also increasingly being attempted by many surgeons. Overall, umbilical port extension is becoming common; and therefore, the risk for IH, especially in the umbilical area, is increasing. However, only few studies have shown tendency of increased IH rate after intracorporeal procedure using extended umbilical incision, especially in gastric cancer surgery [27]. In this present study, it was clearly observed that $\mathrm{IH}$ occurred more frequently after intracorporeal procedure than after extracorporeal procedure. Furthermore, incidence rate of IH was significantly higher with female sex, high BMI, and large tumor.

For gastric cancer surgery, high BMI have been shown as risk factors for IH in previous studies [27]. High BMI has also been consistently identified as a risk factor for $\mathrm{IH}$ irrespective of the type of surgery, site of operation, and use of open surgery or laparoscopic surgery. The results of our study also support existing studies [27].

Most existing studies evaluated risk factors for IH differently by sex, but a previous study on gastric cancer surgery reported female sex as a significant risk factor [27]. IH through umbilical incision was frequently encountered in this study, but the reason for its high incidence among females is unclear. It is supposed that the fat distribution of females is more accumulated in the subcutaneous layer than in intra-abdominal viscera as found in males. Thick subcutaneous fat of obese female patients therefore makes the closure of fascia difficult and results in IH [28].

Large tumor size was also a significant risk factor for $\mathrm{IH}$ in this study. Surgeons attempted to make the smallest possible incisions for extraction of the specimens. The larger the tumor, the larger the specimen, and the longer the incision needed for specimen removal. Hence, extended umbilical incision for removing large specimen during TLRG would have increased the risk of IH [29].

As the result of this study, umbilical wound is more vulnerable to IH than epigastric wound, especially in patients who have risk factors like high BMI, female sex, and large tumor size. Therefore, surgeons should take care to prevent IH in such patients and should be cautious during closure of surgical wound.
Mesh reinforcement could be considered to prevent the recurrence of IH after repair. There were two patients in this study who underwent reoperation due to recurrence of IH after repair. The first patient was 74-year old female patient and she underwent LADG. IH was found at umbilical wound and her BMI was $23.7 \mathrm{~kg} / \mathrm{m}^{2}$. The second operation for recurred hernia was done 6 months after the first hernia operation. The second patient was 52-year old female patient and she underwent TLDG. IH was found at umbilical wound and her BMI was $30.7 \mathrm{~kg} / \mathrm{m}^{2}$. The second operation for recurred hernia was done 1 year after the first hernia operation. In a previous study, mesh reinforcement reduced the recurrence rate of $\mathrm{IH}$ [30]. Therefore, surgeons should be mindful of the possibility of IH recurrence and consider mesh reinforcement during hernia repair in order to prevent recurrence.

This study has several limitations. First, it has the inherent limitations of a retrospective study from one center even though the data volume is large; accordingly, some potential risk factors for IH, such as specific suture technique and wound infection, could not be analyzed. Second, diagnosis of and decision to repair IH were up to surgeons' experiences and preferences. Some surgeons opted for surgical hernia repair, while other surgeons decided on observation for similar cases. Therefore, selection bias could have existed, and the number of IH cases could have been underestimated. Third, these results may not accurately represent the real incidence of IH because not all patients were followed up postoperatively in our institution. Fourth, wound infection and suture material or method could affect IH but those were excluded to analyze because of lack of data. It should be included to analyze in further study.

In conclusion, IH after MIS for gastric cancer patients is not very common. Female sex, high BMI, large tumor size, and intracorporeal procedure were significant risk factors for $\mathrm{IH}$ after MIS for gastric cancer in this study. Therefore, in patients with risk factors, surgeons should cautiously close the surgical wound after MIS for gastric cancer, in order to prevent IH.

\section{NOTES}

\section{Ethical statements}

The Institutional Review Board of the National Cancer Center approved this study (No. NCC2020-0182). The study was conducted according to the principles of the Declaration of Helsinki. Informed consent was waived because of the retrospective nature of the study.

\section{Authors' contributions}

Conceptualization: SCC, KWR 
Formal analysis: All authors

Methodology: SCC, KWR

Writing-original draft: SCC

Writing-review \& editing: All authors

All authors read and approved the final manuscript.

\section{Conflict of interest}

All authors have no conflicts of interest to declare.

\section{ORCID}

Sung Chun Cho, https://orcid.org/0000-0003-2667-4225

Bang Wool Eom, https://orcid.org/0000-0002-0332-2051

Hong Man Yoon, https://orcid.org/0000-0002-6218-7080

Young-Woo Kim, https://orcid.org/0000-0002-1559-9672

Keun Won Ryu, https://orcid.org/0000-0002-5935-9777

\section{REFERENCES}

1. Diener MK, Voss S, Jensen K, Büchler MW, Seiler CM. Elective midline laparotomy closure: the INLINE systematic review and metaanalysis. Ann Surg 2010;251:843-856.

2. Fink $\mathrm{C}$, Baumann $\mathrm{P}$, Wente $\mathrm{MN}$, et al. Incisional hernia rate 3 years after midline laparotomy. Br J Surg 2014;101:51-54.

3. van't Riet M, Steyerberg EW, Nellensteyn J, Bonjer HJ, Jeekel J. Metaanalysis of techniques for closure of midline abdominal incisions. $\mathrm{Br}$ J Surg 2002;89:1350-1356.

4. Athanasiou CD, Robinson J, Yiasemidou M, Lockwood S, Markides GA. Laparoscopic vs open approach for transverse colon cancer. A systematic review and meta-analysis of short and long term outcomes. Int J Surg 2017;41:78-85.

5. Cheng Y, Xiong XZ, Wu SJ, Lin YX, Cheng NS. Laparoscopic vs. open cholecystectomy for cirrhotic patients: a systematic review and meta-analysis. Hepatogastroenterology 2012;59:1727-1734.

6. Xiong JJ, Nunes QM, Huang W, et al. Laparoscopic vs open total gastrectomy for gastric cancer: a meta-analysis. World J Gastroenterol 2013;19:8114-8132.

7. Kössler-Ebs JB, Grummich K, Jensen K, et al. Incisional hernia rates after laparoscopic or open abdominal surgery: a systematic review and meta-analysis. World J Surg 2016;40:2319-2330.

8. Kim HH, Hyung WJ, Cho GS, et al. Morbidity and mortality of laparoscopic gastrectomy versus open gastrectomy for gastric cancer: an interim report. A phase III multicenter, prospective, randomized Trial (KLASS Trial). Ann Surg 2010;251:417-420.

9. Kim YW, Baik YH, Yun YH, et al. Improved quality of life outcomes after laparoscopy-assisted distal gastrectomy for early gastric cancer: results of a prospective randomized clinical trial. Ann Surg 2008;248: 721-727.

10. Lee HJ, Hyung WJ, Yang HK, et al. Short-term outcomes of a mul- ticenter randomized controlled trial comparing laparoscopic distal gastrectomy with D2 lymphadenectomy to open distal gastrectomy for locally advanced gastric cancer (KLASS-02-RCT). Ann Surg 2019; 270:983-991.

11. Han WH, Yehuda AB, Kim DH, et al. A comparative study of totally laparoscopic distal gastrectomy versus laparoscopic-assisted distal gastrectomy in gastric cancer patients: short-term operative outcomes at a high-volume center. Chin J Cancer Res 2018;30:537-545.

12. Han WH, Oh YJ, Eom BW, Yoon HM, Kim YW, Ryu KW. A comparative study of the short-term operative outcome between intracorporeal and extracorporeal anastomoses during laparoscopic total gastrectomy. Surg Endosc 2020;35:1602-1609.

13. Obama K, Kim YM, Kang DR, et al. Long-term oncologic outcomes of robotic gastrectomy for gastric cancer compared with laparoscopic gastrectomy. Gastric Cancer 2018;21:285-295.

14. Parisi A, Reim D, Borghi F, et al. Minimally invasive surgery for gastric cancer: a comparison between robotic, laparoscopic and open surgery. World J Gastroenterol 2017;23:2376-2384.

15. Ooms LS, Verhelst J, Jeekel J, Ijzermans JN, Lange JF, Terkivatan T. Incidence, risk factors, and treatment of incisional hernia after kidney transplantation: an analysis of 1,564 consecutive patients. Surgery 2016;159:1407-1411.

16. Seo GH, Choe EK, Park KJ, Chai YJ. Incidence of clinically relevant incisional hernia after colon cancer surgery and its risk factors: a nationwide claims study. World J Surg 2018;42:1192-1199.

17. Walming S, Angenete E, Block M, Bock D, Gessler B, Haglind E. Retrospective review of risk factors for surgical wound dehiscence and incisional hernia. BMC Surg 2017;17:19.

18. Guideline Committee of the Korean Gastric Cancer Association (KGCA); Development Working Group \& Review Panel. Korean Practice Guideline for Gastric Cancer 2018: an evidence-based, multidisciplinary approach. J Gastric Cancer 2019;19:1-48.

19. Jensen KK, Krarup PM, Scheike T, Jorgensen LN, Mynster T. Incisional hernias after open versus laparoscopic surgery for colonic cancer: a nationwide cohort study. Surg Endosc 2016;30:4469-4479.

20. Lee L, Abou-Khalil M, Liberman S, Boutros M, Fried GM, Feldman LS. Incidence of incisional hernia in the specimen extraction site for laparoscopic colorectal surgery: systematic review and meta-analysis. Surg Endosc 2017;31:5083-5093.

21. Lee L, Mata J, Droeser RA, et al. Incisional hernia after midline versus transverse specimen extraction incision: a randomized trial in patients undergoing laparoscopic colectomy. Ann Surg 2018;268:41-47.

22. Julliard O, Hauters P, Possoz J, Malvaux P, Landenne J, Gherardi D. Incisional hernia after single-incision laparoscopic cholecystectomy: incidence and predictive factors. Surg Endosc 2016;30:4539-4543.

23. Agaba EA, Rainville H, Ikedilo O, Vemulapali P. Incidence of portsite incisional hernia after single-incision laparoscopic surgery. JSLS 2014;18:204-210

24. Alhambra-Rodríguez de Guzmán C, Morandeira-Rivas AJ, HerreroBogajo ML, Moreno-Sanz C. Incidence and risk factors of incisional 
hernia after single-incision endoscopic surgery. J Laparoendosc Adv Surg Tech A 2020;30:251-255.

25. Dhaou MB, Zouari M, Chtourou R, Zitouni H, Jallouli M, Mhiri R. Incidence of incisional hernia after single-incision laparoscopic surgery in children. J Minim Access Surg 2017;13:240-241.

26. Hoyuela C, Juvany M, Guillaumes S, et al. Long-term incisional hernia rate after single-incision laparoscopic cholecystectomy is significantly higher than that after standard three-port laparoscopy: a cohort study. Hernia 2019;23:1205-1213.

27. Jang EJ, Kim MC, Nam SH. Risk factors for the development of incisional hernia in mini-laparotomy wounds following laparoscopic distal gastrectomy in patients with gastric cancer. J Gastric Cancer
2018;18:392-399.

28. Vermillion ST, Lamoutte C, Soper DE, Verdeja A. Wound infection after cesarean: effect of subcutaneous tissue thickness. Obstet Gynecol 2000;95(6 Pt 1):923-926.

29. Comajuncosas J, Hermoso J, Gris P, et al. Risk factors for umbilical trocar site incisional hernia in laparoscopic cholecystectomy: a prospective 3-year follow-up study. Am J Surg 2014;207:1-6.

30. Jairam AP, Timmermans L, Eker HH, et al. Prevention of incisional hernia with prophylactic onlay and sublay mesh reinforcement versus primary suture only in midline laparotomies (PRIMA): 2-year follow-up of a multicentre, double-blind, randomised controlled trial. Lancet 2017;390:567-576. 